\title{
NUESTRAS ANTIGÜEDADES: LA FORMACIÓN DEL CANON POÉTICO MEDIEVAL EN EL SIGLO XVIII
}

por

\author{
EDWARD BAKER
}

Universidad de Florida

RESUMEN: El artículo analiza el estatuto de un corto número de textos clave del canon literario de la Edad Media española antes de la constitución de la Literatura Española como formación macrotextual autónoma inscrita en una cultura plenamente nacionalizada. Dicho análisis plantea los cambios de significación debidos a la transformación del marco institucional en que los textos se transmiten y de la red de relaciones interdiscursivas dentro de las cuales los textos despliegan sus significaciones.

Palabras Clave: Literatura. Canon. Cultura Nacional. Edad Media.

ABSTRACT: The article analyses the status of a small number of key texts of the Spanish Medieval literary canon prior to the constitution of Spanish Literature as an autonomous macrotextual formation inscribed in a fully nationalized culture. This analysis is concerned with shifts of meaning linked to changes both in the institutional setting in which texts are transmitted and in the network of interdiscursive relations within which these texts take on meaning.

KEY WORDS: Literature. Canon. National Culture. Spanish Medieval History.

Si dijéramos que, por poner un ejemplo, el Poema del Cid es una obra maestra de la literatura española medieval haríamos una afirmación que se encuentra en muchas de nuestras historias de la literatura, amén de las cabezas de los estudiosos. Mas si tomáramos una cierta distancia con el propósito de someter a un juicio crítico las categorías en que se fundamenta aquella idea casi universalmente compartida nos encontraríamos en un terreno accidentado, el de la formación de los cánones literarios nacionales de la Europa contemporánea, en donde la solidez de las categorías en que se sostiene nuestra afirmación -literatura, 
Edad Media, España-, se esfumaría como en la copla manriqueña el alegórico rocío de las eras. Dentro de la necesaria brevedad de un apunte, el propósito de las páginas que siguen es poner al descubierto los fundamentos históricos de aquella sfumatura en el marco de la formación, en el último cuarto del siglo XVIII, del canon poético medieval en lengua castellana.

En la actualidad, y a partir del siglo XIX, la literatura española, lo mismo que todas las del entorno europeo, se ha leído enseñado e investigado dentro del marco institucional de los cánones nacionales. El de España, que a partir de las jarchas mozarábicas se extiende a lo largo de un milenio, está dotado de un andamiaje cronológico que se estructura en períodos--Edad Media; Siglo de Oro; Ilustración; Romanticismo; la insistente e inutilizable danza de las generaciones - que, a pesar de su escasa coherencia conceptual, son ampliamente admitidos por quienes nos dedicamos a la historiografía literaria. Por otra parte, desde las primeras décadas del siglo XIX, los textos clasificados como literarios se han venido organizando en torno a autores, géneros y temas que, merced a la casi universalización de la instrucción primaria y secundaria y al crecimiento explosivo de los estudios superiores en fechas recientes, han logrado una cierta resonancia colectiva. Ahora, puesto que la existencia de un canon supone un movimiento oscilante de inclusiones y exclusiones que es consecuencia no únicamente de la intervención de las instituciones pedagógicas sino de la creación de un espacio cultural público de mayor o menor amplitud según las circunstancias históricas y las posibilidades materiales de cada formación social, donde se produce una relación vivencial de escritores y lectores con las letras actuales y las del pasado, el canon puede y debe suscitar cuestionamientos de todo tipo.

Este proceso conduce a menudo a recuperaciones de autores, obras y hasta de géneros literarios enteros y el consiguiente reordenamiento de zonas más o menos amplias del macrotexto que es una literatura nacional. Sabido es que en tiempos relativamente cercanos, si no en el plano estrictamente cronológico sí en el de la estética, las poesías de Góngora fueron objeto de una revaloración a fondo iniciada por Dámaso Alonso en los años 20 que condujo, acto seguido, al replanteamiento global de la poesía y la poética del Barroco. Replanteamiento que fue, a su vez, consustancial con algunos de los mayores logros de la poesía española contemporánea, los de la llamada Generación del 27. Mucho más cercanas son las recuperaciones de escritores cuya obra fue marginada por una ideología que apartaba a las mujeres de la esfera pública de la cultura y que por lo mismo infravaloraba sistemáticamente su obra; de escritores proletarios cuyas aportaciones a una cultura popular de tipo no tradicional fueron arrasadas durante la dictadura, junto con el movimiento obrero en cuyo seno se produjeron; de escritores gay cuya obra ha sido objeto de relecturas desde una perspectiva categórica que encuentra en ella nuevos valores semánticos ${ }^{1}$. Sin embargo,

\footnotetext{
1 Sobre una amplia gama de cuestiones que atañen a la formación de los cánones literarios, pueden consultarse en lengua española las siguientes obras colectivas: SULLA, Enric, comp.: El canon
}

Hispania, LXI/3, núm. 209 (2001) 813-830 
la labor de recuperación y replanteamiento, en sí necesaria y loable, rara vez lleva a cuestionamientos históricos de fondo, acaso porque la reivindicación de obras en principio canonizables que por razones de todo tipo, políticas, ideológicas, o estéticas, habían quedado fuera, parte forzosamente de la necesidad y legitimidad institucional de las categorías que estructuran el canon. Un aspecto fundamental de nuestra tarea es el cuestionamiento mediante la historización de aquellas categorías, puesto que en la actualidad la contradicción fundamental de la historiografía literaria es nuestra capacidad, bastante considerable, de hacer crítica histórica de los textos, frente a la notable incapacidad de historizar las categorías fundamentales - literatura, nacionalidad, etc.- que estructuran el macrotexto canónico.

\section{CONTINUIDAD Y CONTIGÜIDAD}

Hace algo más de medio siglo José María Jover observó que «las palabras más usuales-en Filosofía, en Política, incluso en el lenguaje familiar-nos engañan al rodar de los siglos» debido a los «desplazamientos de significación» y las «transformaciones conceptuales.» «Ello nos invita a meditar en un hecho -agrega el historiador-, que en el campo de la Historia no siempre se ha tenido presente: vocablos que hoy prejuzgamos dotados de un contenido inalterable, significaron antaño cosas distintas a las que significan hoy. El vocablo, las palabras, poco importan en sí. Pero cuando el vocablo encierra en su definición una compleja problemática, merece un intento de análisis. Nación española, Monarquía española, Naciones de España, Reinos de España, Corona Católica, Espa$\tilde{n} a$ : he aquí una colección de expresiones que han de sonar casi como sinónimas en pleno siglo XX, pero que en el XVII fueron capaces de un deslinde conceptual bastante riguroso» ${ }^{2}$. En los años 60 , la distancia que media entre lo que significaron determinadas palabras clave en la Edad Media o Moderna y lo que significan hoy en día, el «desplazamiento de significación» al que aludió Jover, fue abordada en el terreno de la literatura por el bibliófilo y bibliógrafo Antonio Rodríguez-Moñino y por el filólogo inglés Keith Whinnom. Moñino argumentó en 1963, en una conferencia transformada poco después en un ensayo titulado Construcción crítica y realidad histórica en la poesía española de los siglos XVI

\footnotetext{
literario, Madrid, 1998; Pozuelo Yvancos, José María y ARAdra SÁnChez, Rosa María: Teoría del canon y literatura española, Madrid, 2000; PONT, Jaume y SALA-VALldAura, Josep M., coords.: Canon literari: ordre $i$ subversió, Lleida, 2000. Hay, asimismo, un monográfico de la revista Ínsula, el núm. 600, de diciembre de 1996, sobre la formación del canon en España coordinado por POZUELO YVANCOS. En él, y a efectos del presente trabajo, es en especial destacable el artículo de PÉREZ PRIEGO, Miguel Ángel: «Formación del canon literario medieval castellano», 7-9.

2 Jover, José María: «Sobre los conceptos de monarquía y nación en el pensamiento político español del siglo XVII.» Cuadernos de Historia de España, Buenos Aires, XIII, (1950) 101-150. La cita es de la p. 101.
} 
y XVII, lo mismo que Whinnom en Spanish Literary Historiography: Three Forms of Distorsion, discurso de apertura de curso pronunciado en la Universidad de Exeter en el mes de diciembre de 1967, que los historiadores de la literatura éramos víctimas de un conjunto de espejismos fundamentados en una continuidad temporal y una contigüidad espacial ilusorios. Aseveraba el erudito extremeño que

Para mí, la crítica ha construido una realidad inexistente en el tiempo, al proyectar los conocimientos de hoy sobre el pasado, transportando los juicios formulados en presencia de los materiales que poseemos a una pantalla cronológica y deduciendo consecuencias y relaciones.

«Al establecer este mapa, se ha operado con materiales procedentes, en su mayoría, de impresos muy posteriores a la época estudiada, dándoles un valor de irradiación y penetración que no tuvieron. La gran masa lectora de los siglos de oro no conocía todo lo que conocemos; hoy ignoramos mucho de lo que ella conocía. Su panorama era incompleto y parcial; el nuestro también lo es»3.

Una continuidad engañosa que parte de un gravísimo error metodológico, que aqueja prácticamente toda nuestra historiografía literaria, el presentismo, es decir, la traslación más o menos mecánica al pasado de categorías históricas y discursivas contemporáneas, sobreponiendo éstas a épocas y formaciones sociales en que no existían o que, en el mejor de los casos, desempeñaban funciones y desarrollaban significaciones muy distintas de las actuales. Whinnom, por su parte, al plantear la cuestión de las obras que estaban al alcance de un lector de los siglos XV y XVI, puso el dedo en la llaga, llamando la atención al «concepto de continuidad orgánica que determina la mayor parte de lo escrito sobre el tema y que subyace implícitamente en todas las historias de la literatura española» ${ }^{4}$.

Si la historiografía de la literatura española partía - y sigue partiendo- de una continuidad más aparente que real, lo que sucedía en el tiempo sucedía por igual en el espacio. Sobre ello llamó la atención Moñino en su doble vertiente cultural y política, al citar un pasaje procedente de la conocida Introducción a la literatura española del Siglo de Oro del ilustre hispanista alemán Karl Vossler. Argumentaba el estudioso alemán en aquel ciclo de conferencias que había entre los poetas de la época y «su pueblo» una «feliz y envidiable armonía», que los poetas «fortificaban a cada uno de ellos en sus convicciones nacionales y religiosas y en su sentido ético social,» porque "sus creaciones acompañaban, animaban y acompasaban los movimientos del cuerpo nacional con las más

3 Rodríguez-MOÑINO, Antonio: Construcción crítica y realidad histórica en la poesía española de los siglos XVI y XVII, Madrid, $2^{\text {a }}$. Ed., 1968, 55.

4 WhINNOM, Keith: Spanish Literary Historiography: Three Forms of Distortion, Exeter, 1967, 9. Trad. E.B.

Hispania, LXI/3, núm. 209 (2001) 813-830 
elevadas y delicadas vibraciones anímicas de su patria...» ${ }^{5}$. Frente a las gesticulaciones del romanticismo organicista de Vossler argumentaba Moñino que "para aquiescer a esto es preciso suponer que la obra poética era ampliamente conocida; que tal como se puede leer hoy se podía leer en los siglos de oro; que la onda expansiva de la creación personal alcanzaba dilatadas fronteras de público.» Lo que hoy en día se concibe como unidad orgánica, nada menos que el canon poético de una literatura nacional, no lo fue en los siglos altomodernos, por lo que para alcanzar la realidad histórica de aquella poesía, «lo primero es prescindir de hablar de una conciencia nacional colectiva derivada de un colectivo conocimiento nacional. La poesía de los siglos de oro en España está fragmentada en islotes geográficos casi totalmente independientes entre sí y poco permeables... ${ }^{6}$.

Whinnom, por su parte, era más contundente aún, pues comenzó por poner en duda que hubiera una literatura medieval y renacentista que mereciera el calificativo de «española». Acaso bajo el influjo de la metáfora de los «islotes» que había empleado Moñino, argumentó que

«(...) estamos en la Edad Media ante un fenómeno parecido al de un archipiélago, una cadena de islas. El historiador de la literatura española presta atención únicamente a aquellas que están al sol, las obras escritas en lengua vulgar. Pero debajo de la superficie del agua, que constituye una barrera para los hispanistas no anfibios, yace la inmensa cordillera de la literatura medieval latina. Sería una generalización poco exacta afirmar que todas las obras sustanciosas de la literatura española medieval son traducciones. Pero un porcentaje extraordinariamente alto de las obras principales son refundiciones, glosas ampliadas, amalgamas de pasajes prestados y topoi, e imitaciones de obras medievales latinas (y en algunos casos francesas o árabes). [...] Ahora bien, cada investigador por individual se da cuenta de ello; mas persiste (me parece a mí) una suerte de doble visión: la búsqueda de las fuentes de las obras españolas medievales en el latín, el francés o el árabe, pero, simultáneamente, una visión de la literatura medieval española como un continuo orgánico»?.

Al llamar la atención simultáneamente sobre la engañosa «españolidad» de las letras castellanas medievales y la "construcción crítica» (para emplear el término de Moñino) de una continuidad orgánica también engañosa, el estudioso inglés había puesto el dedo en dos llagas a la vez: en primer término, la aplicación presentista de un apelativo nacional anacrónico a unas letras que todavía no eran ni podían ser nacionales, ya que el nacionalismo y sus múltiples $\mathrm{y}$ decisivas incidencias en el terreno de la cultura son muy posteriores ${ }^{8}$. $\mathrm{Y}$ en

5 RODRÍGUEZ-MOÑINO, cit., 15.

6 Ibid, 56.

WHINNOM, cit, 6-7. Trad. E.B.

8 En este razonamiento abunda Claudio GuILLÉn que, con una contundencia nada frecuente en él, observa que la construcción basada en ella de una secuencia textual que en la época en cues-

Hispania, LXI/3, núm. 209 (2001) 813-830 
segundo lugar, la transhistórica organización de determinadas obras en una secuencia textual, en una serie, como habrían dicho los formalistas rusos, serie que en el momento de origen de aquellas obras no existía ni podía existir.

Moñino y Whinnom habían demostrado, cada uno a su manera pero con observaciones metodológicas bastantes parecidas entre sí, que nuestra historiografía literaria se había estrellado contra el muro metodológico del presentismo, al trasladar categorías de nacionalidad elaboradas en el siglo XIX y principios del XX a los siglos medievales y altomodernos en que no eran ni mucho menos plenamente aplicables. A continuación, las categorías así producidas, literatura-española-medieval, por ejemplo, se sometían a una evolución transhistórica en que a partir de la baja Edad Media eran en todo momento iguales a sí mismas como categorías, aunque en el terreno estrictamente empírico sus componentes, las obras planteadas individualmente, estaban sujetos a cambios. Categorías cuyo terminus ad quem era precisamente la España unitaria construida por el nacionalismo del siglo XIX y principios del XX y esencializada por la metafísica nacionalista que, a continuación, para emplear una expresión de Juan Sisinio Pérez Garzón, nacionalizaba el pasado. Círculo metodológicamente cerrado que llevó de manera inevitable a la peculiar apariencia de estabilidad semántica detrás de la cual había, como observó Jover hace medio siglo, una realidad histórica no tan estable?.

\section{ANTIGUOS Y MODERNOS}

Sabido es que de los siglos XVI a XVIII la historiografía dividía el pasado en dos grandes períodos. Por un lado, había una antigüedad que habitualmente asociamos nosotros a la historia y la cultura grecorromanas pero que en realidad abarcaba los algo más de cinco mil años-puesto que manejaban una cronología bíblica-desde que Dios creó el universo mundo hasta el año 1500 aproximadamente. Y por otro, había una modernidad producto de un grado muy elevado de autoconciencia histórica surgida en el Renacimiento y que se contraponía a aquella antigüedad, ahora sí grecorromana, midiendo ante ella sus fuerzas y produciendo a consecuencia de la medición las querellas de antiguos

tión no había ni podía haber existido. , «Digámoslo de una vez: como tal objeto de historia, la literatura nacional es una institución, las más de las veces, desde un punto de vista histórico-literario, no ya insuficiente [...] sino espúrea y fraudulenta. [...] El nacionalismo cultural y literario floreció durante el siglo XIX. Así las cosas, se proyectó y forzó retroactivamente el concepto de historia nacional (como categoría específicamente literaria) sobre indefensas épocas (la Edad Media o el Renacimiento) en que jamás existieron o fueron vigentes o predominantes. Como tal sistema o institución, la literatura medieval francesa o española es un fantasma.» En Teorías de la bistoria literaria, Madrid, 1989, 235.

9 VVAA, Historiografía y nacionalismo español, 1834-1868, Madrid, 1985, 73. Y del mismo autor, en VVAA La gestión de la memoria: La bistoria de España al servicio del poder, Barcelona, 2000, 68 seq.

Hispania, LXI/3, núm. 209 (2001) 813-830 
y modernos que son una de las características fundamentales de la cultura poética, y no únicamente poética, de aquellos siglos. Y digo «querellas» en plural, pues no se trata únicamente de la conocida disputa surgida en el interior de la Académie Française a fines del siglo XVII, sino del surgimiento de una prime$\mathrm{ra}$, aunque lejana, modernidad en la cultura europea. Como simples botones de muestra, las ediciones que hicieron el Brocense y Herrera de las poesías de Garcilaso en el siglo XVI son una vivísima demostración de que un poeta moderno podía contrastar sus armas (o sus letras) con las de la antigüedad latina, y que merecía que la mejor ciencia filológica se pusiera al servicio de tan osada operación. Mas en todo caso, y aunque algunos de los modernos ostentaban una superioridad real o supuesta, la latinidad era el modelo a superar.

En el contexto de este trabajo, interesa la amplia literatura que entre los siglos XVI y XVII surge en torno al tema de las llamadas antigüedades de España. Hacia 1499 Nebrija comenzó a escribir su Muestra de la istoria de las antigüedades de España, obra en cinco libros que en principio debió extenderse desde los primeros habitantes de la península hasta los últimos siglos de la antigüedad, los que entendemos nosotros por la Edad Media. Nebrija no pasó del libro primero de su estudio, cuyo contenido describió con estas palabras: «De las cosas más antiguas de España, hasta que las començaron a enseñorear los carthagineses, quasi ccc años ante del naçimiento de nuestro Saluador.» ${ }^{10} \mathrm{El}$ quinto y último libro, al parecer, abordaría la producción alfonsí y acaso el surgimiento del protohumanismo en el siglo XV, pues trataría «[de] los uarones señalados en letras que ouo en España, i algunos principes, allende los que en los libros passados diximos.» ${ }^{11}$ En los siglos XVI y XVII surge en torno al tema un auténtico género, el de las antigüedades de España, que cuenta con obras de gran importancia en la historiografía española de aquellos siglos.

Género que cuenta con obras de la importancia de Las antigüedades de las ciudades de España de Ambrosio de Morales (1575), el libro de Bernardo José de Alderete, Varias antigüedades de España, África y otras provincias, la Historia de las antigüedades de la ciudad de Salamanca de Gil González Dávila, y la Descripción de la imperial ciudad de Toledo y historia de sus antigüedades y grandeza, y cosas memorables que en ella ban acontecido de Francismo de Pisa. El propósito de estas u otras obras era conectar a España con la Roma también imperial y con el primer cristianismo. Búsqueda, por lo tanto, de un pasado con raíces en la Roma imperial y los primeros siglos del cristianismo por y para un presente también imperial y contrarreformista.

10 Nebrija, Elio Antonio de: Muestra de la istoria de las antigüedades de España, ed. de GonZÁLEZ-LLUBERA, I.: Londres, 1926, 5.

11 NEBRIJA, 206. 


\section{NUESTRAS ANTIGÜEDADES}

El el siglo XVIII, sin embargo, empieza a darse un viraje importante en la idea de lo que constituyen las antigüedades españolas, porque hacia mediados de siglo surge un interés por aquello que hoy entendemos por la Edad Media, que en las periodizaciones de la historiografía dieciochesca seguía formando parte de la Antigüedad. Viraje que da un salto cualitativo en las dos últimas décadas del siglo con la revaloración a fondo de la lengua vulgar y las primeras poesías escritas en la misma. Es necesario, por lo tanto, echar un breve vistazo a lo que se sabía en España de las letras que todavía no eran propiamente medievales y a las condiciones en que se produjo aquel viraje hacia el replanteamiento de la lengua vulgar.

El Diccionario de Autoridades es, en la primera mitad del XVIII, el indicio más claro de lo que a la sazón se sabía, o más exactamente, no se sabía de la poesía en lengua castellana antes de 1400 . Los académicos que confeccionaron el Diccionario, cuyo primer tomo es de 1726 , proporcionaron al lector una «Lista de los autores elegidos por la Real Academia Española para el uso de las voces y modos de hablar, que han de explicarse en el Diccionario de la Lengua Castellana, repartidos en diferentes clases, según los tiempos en que escribieron, y separados los de prosa, y los de verso.» Bajo "Autores de prosa hasta el año de 1200» figura como ficha única El Fuero Juzgo, y «Desde 1200 a 1300» hacen acto de presencia la "Chrónica de San Fernando Rey de España: no se sabe el Autor»; la "Chrónica General del Rey Don Alonso» y «La Historia de Ultramar»; mientras que en el apartado correspondiente al siglo XIV hay un listado que además de «Las Partidas del Rey Don Alonso» y otros textos jurídicos, engloba una serie de crónicas, el «Libro de Montería del Rey Don Alonso» y «El Conde Lucanor, Don Juan Manuel», obra que circulaba en numerosos manuscritos y en una edición impresa por el humanista y genealogista sevillano Gonzalo Argote y Molina en 1575. Bajo el epígrafe de "Autores de verso hasta el año 1200» está «El poema de Alexandro», mientras que "Desde 1200 a 1300» figuran únicamente los «Versos del Rey Don Alonso Décimo». Del siglo XIII se salta directamente y sin contemplaciones al XV, entre cuyos poetas está ciertamente Garcilaso de la Vega. En resumidas cuentas, no hay siquiera en este inventario de las primeras poesías en lengua castellana ni los islotes de Moñino ni el archipiélago de Whinnom sino una tierra de nadie.

$\mathrm{Si}$ los académicos de la época fundacional de la RAE andaban respecto de este tema más bien escasos de noticias, ¿qué es lo que se sabía de este asunto en aquellas fechas? Hacia mediados del siglo hay un par de intentos de abordar históricamente el tema, el breve ensayo del anticuario malagueño Luis José Velázquez, Orígenes de la poesía castellana ${ }^{12}$, y la obra mucho más enjundiosa de un personaje de peso en la historia de las ideas, Fr. Martín Sarmiento, Memorias

12 La obra es de 1754. He consultado la segunda edición, Málaga, 1797.

Hispania, LXI/3, núm. 209 (2001) 813-830 
para la bistoria de la poesía y poetas españoles, trabajo escrito no mucho antes de la muerte en 17.45 del fraile benedictino y colaborador de Feijoo y publicado como primero de los dos tomos de sus Obras póstumas ${ }^{13}$. En las páginas de la $\mathrm{Me-}$ moria dedicadas a la poesía más antigua en lengua castellana ${ }^{14}$, el docto fraile benedictino pasa revista a las noticias que se poseen acerca de Libro de Alexandre, de las poesías de Berceo, del Poema del Cid, del Poema de Fernán_González, del Romancero, etc. Velázquez, cuyo ensayo es mucho más breve y menos detallado, maneja menos información pero habla de Berceo y de la ubicación de algunos manuscritos en el monastero de S. Millán y en la Real Biblioteca de Madrid. ${ }^{15} \mathrm{Da}$, además, algunas noticias, las primeras verdaderamente importantes, acerca de las poesías de Juan Ruiz ${ }^{16}$ y de la ubicación de dos manuscritos, uno en la catedral de Toledo, y otro «en poder de D. Benito Gayoso, oficial archivero de la secretaría de estado [...], parece se llamaba Juan Ruiz y que era Arcipreste de Hita [...]. Yo no he visto este código, aunque está en Toledo al presente, por lo cual no puedo dar razón de lo que acaso contenga más que el de la librería de la Iglesia.... ${ }^{17}$.

Traigo a colación estas breves noticias porque contienen una sugerencia, a saber, que a diferencia de lo que hace pensar la lista de autores y obras que la RAE utilizó para confeccionar el Diccionario de Autoridades, se conocía la existencia de no pocas de las obras que iban a engrosar más adelante el canon poético medieval. Las noticias que se poseían eran indudablemente fragmentarias y, sobre todo, dispersas, pero a lo largo de los siglos modernos se conocía la existencia y la ubicación de manuscritos del Poema del Cid, de las poesías de Berceo, del entonces llamado Libro del Arcipreste, del Libro de Alexandre, del Libro de Apolonio, del Poema de Fernán González, y del Cancionero de Baena, entre otras obras de gran importancia. Y sin embargo, hasta finales del siglo XVIII y el siglo XIX, casi nada de esto se imprimió y, como vamos a ver en breve, lo poco que sí se imprimió vio la luz del día en un contexto institucional que no guarda relación alguna con la formación de un canon literario nacional. Veamos con brevedad dos casos, el de las poesías de Berceo, por un lado y, por otro el del Poema de Fernán González (en adelante PFG).

Se trata en realidad de dos casos muy distintos, porque en el de Berceo se imprimió un poema largo e importante a comienzos del siglo XVIII, mientras

13 Obras póstumas del Rmo. P. M. Fr. Martín Sarmiento, Benedictino. Tomo primero. Memorias para la bistoria de la poesía y poetas españoles..., Madrid, 1775.

14 SARMIENTO, 227 seq.

15 VeláZQUEZ, 34.

16 Ibid, 35 seq.

17 Ibid, 35-36. Por "código" en este contexto es preciso entender codex. Acerca de lo que de Berceo y de Juan Ruiz se sabía desde la baja Edad Media hasta el siglo XVIII pueden consultarse FITZGERALD, J. D.: "Gonzalo de Berceo in Spanish literary criticism before 1780", en Romanic Review I, 1910, 290-301; y MOFfatr, Lucius Gaston: «The Evidence of Early Mentions of the Archpriest of Hita or of His Work", en Modern Language Notes LXXV, January 1960, 33-44. 
que el PFG no vio la luz del día hasta la segunda mitad del siglo XIX y en un contexto que no estimuló apenas su lectura. En 1736 Fr. Sebastián de Vergara dio a la publicidad la conocida hagiografía de Berceo, la Vida de Santo Domingo de Silos ${ }^{18}$. El libro en que se publicó el poema del riojano no es una vida del santo escrita por el propio Vergara, fraile benedictino de la primera mitad del siglo XVIII que había sido abad de Silos y del madrileño monasterio de San Martín y era a la sazón Visitador General de la Congregación de San Benito en España, sino una recopilación de tres obras de los siglos XI a XIII procedentes de Silos que, efectivamente, cuentan la vida y milagros del thaumaturgo español. Como explica Fr. Sebastián en el prólogo, el segundo documento es el poema de Berceo, «hijo de el insigne monasterio de San Millán, que puso en verso castellano lo que de Silos le enviaron en latín.» En este contexto la publicación de su vida de Sto. Domingo en verso castellano más tiene que ver con un asunto institucional, el ensalzamiento de la orden benedictina y con la historia interna de la misma, que con el de la poesía medieval en lengua castellana. Mas poco a poco a lo largo del siglo XVIII se efectuará en el caso de Berceo un cambio de contexto ideológico y discursivo en que, partiendo de las obras de Sarmiento y Velazquez y culminando con la publicación en 1780 por Tomás Antonio Sánchez del tomo segundo, el correspondiente a las poesías de Berceo, de la Colección de poesías castellanas anteriores al siglo XV, el riojano se inserta textual y contextual con cada vez mayor independencia frente a su orden religiosa en la historia de la poesía castellana primero y, a continuación, en el macrotexto de la literatura española. Transformación institucional que tiene un paralelismo en la secularización y nacionalización de las posibles lecturas de Berceo en que se dejan atrás la hagiografía y las devociones propias del antiguo régimen, y paulatinamente a lo largo de los siglos XIX y XX se van ubicando en primer plano la crítica literaria y la filología, lecturas que se realizan dentro del marco de una literatura ya plenamente nacional.

El caso del PFG es algo menos claro porque no se trata del traslado de unos textos de un contexto institucional a otro, con las consiguientes transformaciones funcionales y semánticas, sino de un hecho no consumado, de una ausencia históricamente determinada. He aludido ya al hecho de que el humanista Gonzalo de Argote y de Molina publicó una edición de El Conde Lucanor de don Juan Manuel ${ }^{19}$. Curiosa excepción, pues si rastreamos las obras canónicas de lo que desde hace dos siglos clasificamos como literatura española medieval, con la sola excepción de la Vida de Santo Domingo de Berceo, no había ni una sola que en los siglos modernos se llevara a la imprenta. Hay, ciertamente, una abundante muestra de crónicas pero, salvedad hecha de la obra que Argote llevó a

\footnotetext{
18 VeRGARA Fr. Sebastián de: Vida y milagros de el thaumaturgo español, Moyses segundo, redemptor de cautivos, abogado de los felices partos, Sto Domingo Manso, abad benedictino, reparador del real monasterio de Silos...Madrid, 1736./IIII

19 Sevilla, 1575. He consultado la segunda edición, Madrid, 1642.

Hispania, LXI/3, núm. 209 (2001) 813-830
} 
la imprenta, la literatura imaginativa brilla en el mundo de los impresos por su ausencia. El hecho es doblemente llamativo pues Argote, además de humanista, era un importante bibliófilo que poseía, entre otras cosas, sendos manuscritos del PFG y del Libro de buen amor ${ }^{20}$. Entonces surgen inevitablemente dos preguntas. En primer lugar, ¿̇por qué Argote publicó la obra de don Juan Manuel? Y en segundo lugar, dadas las muestras de su más que evidente interés por las primeras poesías en lengua castellana, ¿por qué no se molestó en publicar tan-para nosotros-importantes obras poéticas?

Las respuestas inevitablemente son varias. Para Argote, que era genealogista, don Juan Manuel tenía como aval indiscutiblemente importante su condición, pues como dice Argote en su «Discurso al curioso lector», se trataba de "resucitar la memoria de tan excelente príncipe», nada menos que sobrino de Alfonso X el Sabio y nieto de San Fernando, autor de un libro, El Conde Lucanor, que gira precisamente en torno a la educación de la nobleza, tema de capital importancia para el humanismo renacentista. Por otra parte, el humanista sevillano alaba las muestras de «pureza y propiedad de nuestra lengua» de la prosa manuelina ya que, con criterio horaciano, mezcla «lo dulce con lo provechoso». A continuación, esgrime un argumento en que contrasta los gustos de los lectores del siglo XVI en materia de narrativa con lo contenido en $E l$ Conde Lucanor: "Y si los libros de novelas y fábulas tienen lugar y aceptación pública, los cuales tienen un solo intento que es entretener con apacible y algunas veces dañoso gusto, más justamente deber ser aceptado este libro, pues además de gustoso tiene, como dicho tengo, tan buena parte de aprovechamiento».

Por lo que respecta a las poesías, hay alguna muestra de las de Juan Ruiz en un inventario de la biblioteca que poseía Argote, pues en ella figura un "Cancionero del Arcipreste, de canciones antiquissimas de tiempo del Rey Don Alonso XI» ${ }^{21}$. Mas no está claro que Argote poseyera un manuscrito relativamente completo o que hubiera leído aquello que poseía. El caso del PFG es más interesante porque Argote lo sacó a relucir en su «Discurso de la poesía antigua castellana» incluida en la edición de $E l$ Conde Lucanor, muestra clarísima de su interés y conocimiento en un terrero que en pleno Renacimiento no parecía suscitar ni una cosa ni otra. En el «Discurso» se refiere a los versos de arte mayor, dando "este exemplo de una historia antigua en verso del conde Ferrán Gonçález, que yo tengo en mi museo, cuyo Discurso dice así»:

$$
\begin{aligned}
& \text { «Esconces era Castilla un pequeño rencon } \\
& \text { era de Castellanos Montedoca mojon } \\
& \text { y de la otra parte Fitero fondon } \\
& \text { Moros tenian Carraço en aquella sazon. }
\end{aligned}
$$

\footnotetext{
20 Acerca de la biblioteca de Argote de Molina, véanse LóPEZ Martínez, Celestino: Algunos documentos para la biografía de Argote de Molina, Sevilla, 1921, 80-83; y Millares CARLO, Agustín: «La biblioteca de Gonzalo Argote de Molina», Revista de Filología Española X, 1923, 137-152.

${ }^{21}$ Millares Carlo, 145.
} 


\author{
Era toda Castiella solo un alcaldia \\ maguer era poca et de poca valia \\ nunca de homes buenos ella fue vazia \\ de quales ellos fueron paresce oy en dia \\ Varones castellanos fuera su cuydado \\ llegar su señor a mas alto estado \\ de una alcaldia pobre fizieron la condado \\ tornaron la dempues cabeça de reynado \\ Ovo nombre Ferrando el conde primero \\ nunca ovo en el mundo atal cavallero \\ fue este para moros mortal omiziero \\ dezien le por las lides el buytre carnicero»22.
}

Parece lógico que Argote se aprestara a publicar un poema sobre dos temas tan fundamentales como el nacimiento del reino de Castilla y la Reconquista, pero al abordar este problemático terreno lo primero que debemos hacer es desbrozar para, a continuación, distinguir entre criterios actuales marcados por el nacionalismo españolista y la visión que de España o de las Españas se tenía lo mismo en la época altomedieval que en los siglos modernos. En ese desbroce habría que empezar por el tema de la Reconquista, distinguiendo entre dos momentos históricos muy separados entre sí. El primero es el altomedieval en que las monarquías de nuevo cuño surgidas en los siglos posteriores a la invasión musulmana oponían una resistencia que, a su vez, generó una ideología restauradora de Hispania en la que va envuelta una estrategia legitimadora. ${ }^{23}$ Estrategia de legitimación basada en la idea de la esencial continuidad entre los godos y las monarquías asturleonesa y castellana, por lo que ellos serían los herederos legítimos y restauradores de Hispania.

Después de desplegada la estrategia de legitimación de las monarquías cristianas altomedievales, hay un segundo momento muy separado cronológica e ideológicamente. La historiografía nacionalista de los siglos XIX y XX construyó una empresa reconquistadora que duró cerca de ocho siglos en cuyo interior se forjó ya de forma definitiva la nación española, por definición católica. Dicha historiografía, empezando muy destacadamente por la Historia de España de Modesto Lafuente, convirtió la Reconquista prácticamente en espina dorsal

22 Cito por la edición moderna, Discurso sobre la poesía castellana, ed. de Eleuterio F. Tiscornia, Madrid, 1926, 36. Aunque el acaudalado Argote poseía una colección de pinturas nada desdeñable, en este contexto la palabra «museo» más se aproxima al modelo del studiolo renacentista que a lo que actualmente entendemos por tal.

23 Para la Reconquista y la restauración de Hispania, véase Maravall, José Antonio: El concepto de España en la Edad Media. Madrid, 1964, $2^{\text {a }}$ ed, cap. VI.

Hispania, LXI/3, núm. 209 (2001) 813-830 
de la nacionalidad española ${ }^{24}$, y a fines del siglo XIX y comienzos del XX se empezó a dar a aquel nacionalismo un viraje castellanista virulentamente centralizador y esencializante ${ }^{25}$. Ahora bien, cuando en nuestro mundo se habla de la Reconquista se efectúa comúnmente una fusión de ambos momentos, tan distintos entre sí, por lo que se tiende a construir un continuo nacional altísimamente cuestionable hecho de una concatenación de ideas y sentimientos políticos y creencias religiosas, de hazañas bélicas y figuras históricas envueltas en un vaho legendario que comenzaría con don Pelayo y llegaría sin fisuras hasta el nacionalcatolicismo de nuestra época. Aquella (con)fusión de dos momentos históricos radicalmente distintos pero profundamente mitificados y la consiguiente narración mítica constituiría el basamento, para evocar el título de la conocida obra de Benedict Anderson, de la comunidad imaginada por los españoles.

Volvamos a Argote y a su manuscrito del PFG. Desde la perspectiva del nacionalismo españolista parecería no ya lógica sino un deber de patriotismo la publicación de un poema importante que canta y cuenta la fundación de Castilla y la Reconquista, máxime cuando cita las estrofas del poema en que se comienza a contar la historia de Castilla, y sin embargo no es así. Porque esta perspectiva, propia del nacionalismo decimonónico, no es la de Argote, que no era ni nacionalista ni castellanista. Además, desde la perspectiva de una supuesta literatura española, que ni existía ni podía existir en el siglo XVI, la descripción que da Argote al poema sobre el conde castellano es precisamente de «una historia antigua en verso». En el inventario de la biblioteca el PFG figura como «Crónica del Conde Fernán González en verso antiguo castellano» ${ }^{26}$. En definitiva, para Argote el PFG es una «historia» o una «crónica» en verso cuya publicación no interesaría especialmente en un siglo XVI en que la Crónica de Fernán González andaba impresa en numerosas ediciones ${ }^{27}$. En definitiva, para Argote el PFG no era un poema. Era otra cosa, mejor o peor pero otra cosa que no merecía la pena trasladar al mundo de los impresos porque había ya una versión en prosa, una crónica que contaba las hazañas del conde castellano y que estaba al alcance de todos los inteligentes en aquella materia. Materia que, ciertamente, no tenía en la segunda mitad del siglo XVI las resonancias ideológicas que tendría tres siglos más adelante, cuando por fin se publicó

24 De ahí la objeción de Ortega en España invertebrada, ya que la historia de España carecería de vertebración.

25 Para la crítica de la idea de la Reconquista en sus dos vertientes, la del continuismo altomedieval y la del nacionalismo contemporáneo, véase BARBERO, Abilio y VIGIL, Marcelo: Sobre los orígenes sociales de la Reconquista, Barcelona, 1974; y de los mismos autores, La formación del feudalismo en la península ibérica, Barcelona, 1978, en especial el capítulo 6, «La historiografía de la época de Alfonso III", 232-278.

26 Se trata de la ficha núm. 10 de la biblioteca. Ver Millares Carlo, 144.

27 Véanse en el Manual de Palau las fichas 87745 a 87775. 
el PFG en la Biblioteca de Gallardo ${ }^{28}$. Y no hay que sorprenderse demasiado, pues un par de siglos después de que Argote no imprimiera el PFG, el ilustrado Antonio de Capmany emitió un juicio bastante parecido al plantear el tema de los primeros poemas en lengua castellana, que, aseveraba el ilustrado barcelonés, «más se deben mirar como prosa rimada que como poesía. Así pues, no los trasladó como modelo ni del uno ni del otro género, sino como muestras del estado y carácter de la lengua en aquella edad de su infancia» ${ }^{29}$. Para haber publicado el PFG o cualquiera de las poesías antiguas castellanas cuya existencia se conocía, poco o mucho, en los siglos modernos, habría sido necesario que la cultura más elevada planteara una revalorización de la lengua vulgar y de toda la poesía escrita en ella, una revisión a fondo capaz de romper con los modelos dominantes de lo que desde el Renacimiento hasta el neoclasicismo constituía la elocuencia, lo mismo en verso que en prosa. Revisión que no se produjo ni se pudo producir, por lo que salvo el caso de la Vida de Sto. Domingo de Silos de Berceo, obra impresa en un marco ideológico y discursivo absolutamente ajeno a esas cuestiones, prácticamente nada de lo que hoy constituye el canon poético medieval se imprimió hasta que un bibliotecario de la Real Biblioteca, Tomás Antonio Sánchez, lanzó su Colección de poesías castellanas anteriores al siglo $X V^{30}$.

La Colección consta de cuatro tomos editados por D. Antonio de Sancha entre 1779 y 1790 con detallados estudios preliminares y glosarios confeccionados por el P. Sánchez, ya que en las últimas décadas del siglo XVIII eran muy contadas las personas que estaban en condiciones de leer estas poesías. Los cuatro tomos contienen El poema del Cid (tomo I, 1779); las poesías de Berceo (tomo II, 1780), el Libro de Alexandre (tomo III, 1782) y el Libro de buen amor (tomo IV, 1790). Hay en Sánchez un cambio importante en la apreciación del lenguaje poético en lengua vulgar y en el valor histórico de estas primeras poesías. Apreciaciones que en realidad son justificaciones, pues en el momento de auge del neoclasicismo era preciso justificar la publicación de un poema como el del Cid en donde «no hay que buscar... muchas imágenes poéticas, mitología, ni pensamientos brillantes, "y se caracteriza por lo que el propio Sánchez

28 GallaRdo, Bartolomé José: Ensayo de una biblioteca española de libros raros y curiosos, Madrid, tomo I, 1863, núm. 711, cols. 763-803. Se reimprimió casi inmediatamente después en la edición de Florentino Janer, BAE, LVII.

29 CAPMANY, Antonio de: Teatro bistórico-crítico de la eloqüencia española, Madrid, 1786-1794, 5 tomos. La cita de del «Discurso preliminar», cxiii.

30 Hay una excepción de menor cuantía, ya que en 1766, trece años antes de que Sánchez empezara a imprimir su Colección Cándido María Trigueros citó los primeros 197 versos del Poema del Cid en su Disertación sobre el verso suelto y la rima, para leer en la Real Academia de Buenas Letras de Sevilla. Sin embargo, la Disertación de Trigueros no se imprimió. Sí se imprimieron trece versos del cantar cidiano en las Poesías filosóficas del autor. V. AGUILAR PINAAL, Francisco: «Cándido María Trigueros y el Poema del Cid», en Nueva Revista de Filología Hispánica XXXIII, 1984, 224-233. Acerca de las noticias del Poema del Cid que poseían los estudiosos antes de que lo imprimiera Tomás Antonio Sanchez en 1779, véanse las páginas 228-229 del art. de AGUILAR PIÑal.

Hispania, LXI/3, núm. 209 (2001) 813-830 
califica de "venerables prendas de rusticidad». Sin embargo, en el cantar cidiano «todo es histórico, todo sencillez y naturalidad». Además, "hay en este poema ironías finas, dichos agudos, refranes y sentencias proverbiales que no dejarán de agradar a los que las entiendan; sobre todo reina en él un cierto aire de verdad... Y no le falta su mérito para graduarse de poema épico...» ${ }^{31}$.

Pero mucho más que las justificaciones interesan las consecuencias para la historiografía literaria, porque Sánchez reunió algunas de las condiciones de posibilidad para escribir una historia de la poesía en lengua castellana. Ello se debe a la doble ruptura que efectuó en los cuatro tomos de la Colección, una metodológica en sentido protohistoricista, y otra ideológica en sentido protonacionalista. En el orden metodológico Sánchez repudiaba la normatividad del neoclasicismo con respecto a lo que en poesía constituía la belleza y la elocuencia, lo que a su vez ensanchaba el terreno que en principio podía ocupar la poesía, abriendo un nuevo espacio para la historia donde tendría carta de naturaleza toda la poesía en lengua castellana sin excepción alguna. En el prólogo del tomo I argumenta el bibliotecario de la Real Biblioteca que, ausente todo o casi todo lo anterior al siglo XV, la poesía castellana era un edificio sin cimiento

«(...) cuya falta causaba no pequeño vacío de una buena parte de nuestra literatura. Ahora se intenta llenar para que los curiosos, amantes de lo nacional y de nuestras antigüedades, vean no sólo la formación de la poesía castellana y sus primeros incrementos, sino también la de nuestra lengua. Veráse que nuestra poesía rimada no empezó por Juan de Mena, Boscán y Garcilaso, como por falta de instrucción algunos han afirmado» 32 .

Al mismo tiempo, la reivindicación precisamente de nuestras antigüedades posibilita la constitución, siempre en el terreno de la poesía, de una nueva periodización, pues abre una zanja entre dicha poesía y lo que en los siglos XVI y XVII se había entendido por antigüedades de España. Aunque Sánchez no hace referencia en ningún momento a una "Edad Media», concepto con el que no parece estar familiarizado ${ }^{33}$, está claro que la recuperación y el estudio a fondo de unas antigüedades que fueran rigurosamente nuestras exigía una nueva periodización, porque en la historiografía de los siglos modernos, la división

31 I, 229

32 I, prólogo, 6. El subrayado es mío. Por otra parte, en este contexto hay que entender la voz «literatura» en su acepción moderna y no contemporánea, o sea, las letras humanas en conjunto. Véase al respecto el importante trabajo de URZAINQUI, Inmaculada: «El concepto de Historia Literaria en el siglo XVIII», en VVAA, Homenaje a Álvaro Galmés de Fuentes, III, 565-589.

33 Jovellanos sí, porque en su "Censura de la Real Academia de la Historia», justificaba la lectura de las poesías del Arcipreste, que «tienen toda la recomendación que permiten el siglo y la materia en que fueron escritas; y si cabe, alguna preferencia en su mérito respecto de las que se han publicado hasta ahora, también acreedoras a ella, pues pudiendo servir igualmente que las otras al estudio de nuestra lengua y poesía vulgar, pueden además ser muy provechosas para el de los usos y costumbres de la edad media». IV, xxx. 
entre antigüedad y modernidad relegaba los siglos que corresponden a la Edad Media a una indefinición producto de la indiferencia, cuando no del desprecio. Eran los «siglos bajos» de que habla repetidamente el jesuita exiliado Juan Andrés en Dell' origine, progressi e stato attuale d'ogni letteratura. ${ }^{34}$ Ahora, a pesar de su distanciamiento de aquellos siglos oscuros, el abate Andrés periodiza casi en el mismo sentido que Sánchez, pues argumenta que el surgimiento de la poesía en lengua vulgar, hecho que para el jesuita español se produce en Toledo en el siglo XI, es indicio del comienzo nada menos que de la edad moderna. «Infatti, puntualiza Andrés, se noi vorremo cercare un' epoca determinata della volgare poesia e dal coltivamento delle lengue moderne, potremo assai fondatamente fissarla nella conquista di Toledo, fatta da Alfonso VI nel 1085.»35 En estas páginas tampoco aparece la idea de una edad media entre la antigua y la moderna, pero al distinguir este autor entre una y otra por el surgimiento de la lengua vulgar frente al latín, hace la misma operación que Tomás Antonio Sánchez en el deslinde de nuestras antigüedades, por lo que llama la atención velis nolis sobre la necesidad de una nueva periodización.

Los «siglos bajos» ciertamente pertenecían a la antigüedad, mas por su falta de luces eran los peores momentos de la misma. De ahí que el gran polemista y defensor de las ideas ilustradas, Juan Pablo Forner, recibiera la publicación de la Colección con sorna, reprochando a Sánchez su erudición "tan ducha en el conocimiento de nuestras antiguallas» ${ }^{36}$ Forner se queja, a continuación, de los "gruesos tomos de notas sobre algún cartapelón del siglo XIII en loor de las bragas del Cid...» ${ }^{37}$. Acto seguido hay contestación de Sánchez y contrarréplica de Forner y otra de Sánchez, zafarrancho literario que, como a menudo sucede en estos casos, arroja más calor que luz sobre el asunto. Sin embargo, como señala Pedro Sáinz Rodríguez, la polémica es importante "considerada como documento para comprender el choque de las dos mentalidades: la histórica y la neoclásica.... ${ }^{38}$. Si las primeras poesías en lengua castellana eran nuestras antiguallas en lugar de nuestras antigüedades para nada se necesitaba una Edad Media, pues con la burla y el denuesto bastaba, pero en una narrativa histórica abarcadora de toda la poesía y de características protonacionalistas sí, porque como puntualiza José Carlos Mainer a propósito del primer romanticismo, «la ruptura de la ecuación belleza-perfección quiebra las bases que sustenta el ideal clásico y la idea de evolución, aplicada al pasado, permite una contemplación puramente histórica de los siglos oscuros» ${ }^{39}$.

\footnotetext{
34 Parma, 1782-1799, 7 tomos.

35 I, 279-280.

36 Forner, Juan Pablo: Carta de Bartolo, Madrid 1790, 11. El subr. es mío.

37 Cit. 66.

38 Véase su Historia de la crítica literaria en España, Madrid, 1989, 131.

39 «De historiografía literaria española», en VV AA, Estudios sobre bistoria de España. Homenaje a Manuel Tuñón de Lara. Madrid, 1981, tomo II, 440.
}

Hispania, LXI/3, núm. 209 (2001) 813-830 
Y ésa es la segunda ruptura que efectúa Sanchez en la Colección. Entonces, partiendo de una revalorización a fondo de la lengua vulgar y sus expresiones primitivas, aquellas poesías tendrían un valor y un interés no porque igualaran en belleza y altura de miras las de Horacio y Virgilio en la antigüedad o las de Garcilaso (o de cualquier poeta neoclásico de mucha menos entidad) en la edad moderna. No merecerían figurar en una antología de la poesía como el Parnaso español de López Sedano, o en el Teatro de la elocuencia española de Capmany. Serían mejores o peores pero interesarían por un motivo poco menos que ontológico, por ser nuestras. A partir de esa condición radicalmente particularista tendrían un valor, ya que sin ellas no se podría hacer una historia propiamente nacional de la poesía. Y esa nueva narración que constituiría una posible Historia de la poesía castellana desde sus primeros momentos hasta las últimas décadas del siglo XVIII supondría una nueva organización narrativa, una nueva periodización, porque la en aquel entonces vigente no sería capaz de englobar los hechos que sería preciso movilizar para hacer esa nueva historia. En resumidas cuentas, la doble ruptura que efectuó Sánchez nos sitúa en los umbrales de la bistoria de la literatura española en el sentido que desde hace casi dos siglos hemos ido dando paulatinamente a esas palabras. 